\title{
Cost-benefit analysis: applications to restoration of rivers
}

\author{
F. J. Hitzhusen \\ The Ohio State University, USA
}

\begin{abstract}
This paper draws on the author's 30+ years of experience teaching and applying cost-benefit analysis. For the past nine years he has also directed a large research program at The Ohio State University to develop estimates of the benefits and costs of various water quality, infrastructure, scenic and historic river corridor impacts and improvements as a guide to investment planning and public policy on river and related watershed restoration. The research is focused on the evaluation of eight rivers in the Great Lakes region of the United States and involves a team of environmental economists, an ecological engineer and two aquatic biologists. When the various river corridor benefits or values broadly conceived are expressed in a common economic metric and compared to their full economic costs, one has a basis for assessing river corridors in an investment planning, economic development, welfare economic and public policy context.

Keywords: cost-benefit, river restoration, water quality, infrastructure, investment planning.
\end{abstract}

\section{Introduction}

Prest and Turney have described cost-benefit analysis (CBA) as a practical way of assessing the desirability of public projects where both a long and wide view are important i.e., all relevant costs and benefits over the full life of the project are considered. Others (see Burkhead and Miner [4]) have viewed CBA as the operational side of fiscal theory concerned with quantifying and evaluating public output for more "rational" public investment planning and decision making. A major subset of CBA is the valuation of non-market benefits and costs, particularly relating to natural resource projects and environmental impacts. Although consensus on the underlying theory is strong (Dasgupta and Pearce [6]), many practical problems and pressures have been encountered over the history of CBA and its applications (see Hitzhusen $[10,11]$ ). 
Treatment costs, hedonic pricing, contingent valuation, benefit transfer and capture estimation, aquatic biology, and hydrodynamic-ecologic simulation models and methods are developed to value river corridor impacts. Impacts include household waste, pesticides, industrial toxics, gravel mining and agricultural run-off as well as improvements such as household waste treatment, dredging of toxics, zoning, greenways, dam removals, dam and lock upgrades, bike trails, towpaths, ramps and other recreational infrastructure. Some important innovations are introduced for codification of river supply and demand factors, testing for scope, context and sequence effects in CVM mail surveys, benefit transfer and capture, structured elicitation groups for assessing constructed vs. static preferences, distribution impacts and equity weighting for contaminated river segments and integration of economic, ecologic and aquatic models for assessing dam removal. A case study of the Muskingum River corridor is developed in this paper to illustrate several of the foregoing valuation methods in doing a cost-benefit analysis.

The Muskingum River, which flows 75 miles through four counties in an economically depressed region of Southeastern Ohio in the Great Lakes region of U.S., provides an example of the roles a river can play in regional development. Although the Muskingum tributary is small relative to the Mississippi Basin of which it is a part, it illustrates many important issues of investment planning and public policy. Throughout the length of the river are 10 sets of locks and dams that were constructed between 1837 and 1841 to facilitate transport of products by barge. The original features of the locks have been maintained throughout the century, making them an interesting attraction for boaters and anglers as well as for tourists, even though little cargo moves through them now. This two-phase study has focused on one river corridor and its relevant impacts and improvements including the repair of historic dams and locks, extension of an existing bike trail, improvement of household septic systems and the past establishment of municipal zoning.

The methods applied for estimating costs in this study are primarily marketbased opportunity cost concepts. Benefits are more difficult to observe in market transactions for each of the corridor improvements, so the authors used hedonic pricing and contingent valuation survey methods, benefit transfer from previous related studies and benefit capture. In all cases conservative assumptions are made in order to provide lower bound estimates of net benefits and to avoid overstating the economic merits of the selected corridor improvements. In order to easily compare benefits and costs that are occurring over time, both the benefits and costs are expressed in 1999 dollar values at a 10 percent discount rate.

\section{Concepts and methods}

A well-developed method called hedonic pricing was chosen to measure the effect of corridor improvements such as zoning and septic systems on residential property values. Hedonic pricing is a method of statistically determining the amount paid for housing and community attributes as well as for environmental 
goods. A basic concept of the hedonic model is that the value of an asset, in this case a home, is a function of a set of characteristics; this function is known as the hedonic price function. This can be expressed as: $P=f(S, C, Q)$, where $P$ is the price or value of the house, $\mathrm{S}$ is a vector of housing characteristics, $\mathrm{C}$ is a vector of community characteristics and $\mathrm{Q}$ a vector of environmental characteristics. Hedonic pricing involves decomposing property prices into their relevant components (as expressed above) to reveal the amount by which consumers value the environmental amenities and disamenities being studied. Using the hedonic function, we can estimate the change in the asset value, in this case property value, as a result of a change in any characteristic, while holding all other characteristics constant. This change is measured by the coefficient by which that characteristic is multiplied.

Zoning regulations are included in the hedonic equation developed by Ayalasomayajula to represent one community characteristic. Jud concluded in his study on the effects of zoning on residential values in North Carolina that "purchasers of residential housing seek a uniformity in neighborhood land use... and are willing to pay a premium for it" [14]. An important purpose of zoning is to protect the neighborhood residents from externalities (such as decreased property value) arising from undesirable uses of land in the same area. Zoning increases the value of land in the neighborhood by preventing these uses. The purpose of zoning in any city or township is to promote the health, safety and welfare of the citizens of that region. It is considered to be an important factor in the allocation of property rights to the residents of the region. Further, zoning contributes to the tax base of the region and it is generally the case (e.g. Hite [9]) that property bidders include the higher tax rate when bidding for a property with such attributes.

Another set of community characteristics is represented by the cost and quality of the school system; 'high school graduation rate' was included as a proxy output. Expenditure per pupil was not included as an input variable, because the school districts in the corridor were of vastly different sizes. Distance to the three urban centers (Marietta, McConnelsville and Zanesville) is intended to provide a measure of relative locational advantage. A dummy variable specifying whether a property has direct river access or not, is intended to measure an environmental amenity, but lack of data made it difficult to include water quality in our model. Earlier work by Epp and Al-Ani [7] found that river water quality has a positive impact on nearby non-farm residential property values.

A Contingent Valuation survey of the general adult population of Ohio (a random sample of licensed drivers) was designed based on the standard reference: Using Surveys to Value Public Goods: the Contingent Valuation Method by Carson and Mitchell. A payment card format was used to determine willingness to pay for a bike path extension and improved treatment of household waste. In order to identify the characteristics of people who are willing to pay for the locks and dams, bike trail and/or septic program, we utilized bid functions. A bid function explains willingness to pay (WTP) as a function of various demographic and other characteristics of the respondent. 
Community leaders and policy makers could use this information to identify what constituency they should be targeting in legislative, referendum or fund raising efforts. By contacting or soliciting only those people who are likely to vote favorably or contribute, transaction costs could be reduced and the probability of success increased.

Boyle and Bergstrom [3] define benefit transfer as "the transfer of existing estimates of non-market values to a new study which is different from the study for which the values were originally estimated". They refer to the area from which the values originated as the "study site" and the area to which the values will be transferred as the "policy site". Several problems are inherent in the transfer process. In particular, the commodity, site and population characteristics of the study site must closely approximate those of the policy site. However, benefit transfer plays an important role in resource economics; it provides a rough estimate of benefits for sites where primary data collection is prohibitively expensive and/or time consuming.

The benefit transfer values used for this study were derived from a 1992 meta-analysis published by Walsh et al. [20]. The authors reviewed 120 outdoor recreation studies from sites in the U.S. between 1968 and 1988. They estimated benefits resulting from various recreational activities including camping, fishing, boating, hunting, picnicking, swimming and sightseeing. In their article, Walsh et al. gave the activities and their median values per recreator day in 1987 dollars. The values from Walsh et al.'s study were appreciated to 1999 dollars using a consumer price index (CPI).

For this study we deflated the day use values to reflect the median household income for the three county area which is lower than that of American households which are more relevant to the Walsh study. Because the proportion of motorized to nonmotorized boating on the river was unknown, the average of the two values was used to calculate the benefits. On average, lock visitors probably do not spend more than an hour at a site and it is unknown whether or not they stop at more than one lock, or other river businesses. Furthermore, the magnitude of the average annual visitation to locks was suspiciously large. Therefore, a very conservative assumption was made and the value of visitation supplied by the Walsh study was divided by eight for use in this study. This resulted in a value of $\$ 3.11$.

In environmental economics benefit capture generally relates to attempts by environmental economists to estimate non or extra market values for various natural resource projects or policy initiatives. Pearce and others have suggested that environmental economics is concerned with not just the measurement or estimation but also the capture and internalization of benefits and costs from environmental service and residual flows. Considerable research activity over the past 20 years or more has been concerned with non-market valuation techniques for measuring and transferring the economic benefits including nonuse values of various environmental goods and services (e.g., Walsh et al. [20], Smith, Boyle and Bergstrom [3], French and Hitzhusen [8]). Less attention has been given to how some of these benefits could be captured and by whom in a real world policy context. 
From our review to date, it is evident that the concept and protocol for benefit capture is not clearly defined in the literature. For example, early research by Bishop et al. [2] found differences between willingness to pay and willingness to sell as well as differences between hypothetical and actual WTP for goose hunting permits in Wisconsin. Many subsequent studies have had similar findings. Actual WTP would appear relevant in assessing benefit capture if one is concerned about increasing the probability of non market WTP values actually being paid.

It is also clear that benefit capture is not a homogenous phenomenon. For example, one could posit a continuum with pure private market goods at one end and pure public goods at the other. Samuelson actually set this up as a dichotomy in his classic "The Pure Theory of Public Expenditure" [18]. Randall protests the use of the concept of "public goods" and proposes in its place four categories of goods: divisible exclusive goods; divisible, non-exclusive goods; indivisible exclusive goods and indivisible, non-exclusive goods. This is helpful since a benefit capture related continuum useful for natural resource and environmental policy would appear to have several points. Using the river corridor example, bait shops and other private businesses on the river would expect direct revenue increases and the resulting sales tax increases from more recreational use of a river with higher water quality. Likewise, property values may also increase, but benefits are not captured by the owners unless they rent the property or until they sell. However, as soon as the assessed value of the property increases, increased property taxes will accrue to local governments and school districts unless millage rates are decreased. Hedonic pricing can empirically establish the implicit prices of various amenities or river corridor improvements and these first stage hedonic models can in turn be linked to tax revenue functions through the millage rates.

Attempts to estimate WTP for some preservation or non-use values of the river corridor with CVM survey methods provides additional points on the continuum. With careful CVM protocols these values can be accurately estimated, but those responsible (e.g., local and state governments) for corridor improvements generally don't receive any immediate payments from the CVM based WTP of bidders. The CVM aggregate WTP evidence could be used to eventually increase public support for increased taxes to upgrade corridors. In addition, carefully constructed bid functions, may identify demographic factors associated with WTP that could make efforts to increase taxes and/or fund raising more effective. This paper explores hedonic pricing and CVM approaches for answering these questions in the context of a benefit cost analysis of several proposed upgrades to the Muskingum River corridor in SE Ohio (Hitzhusen et al. [13]).

\section{Results of analysis}

\subsection{Infrastructure and water quality results}

Earlier US Army Corps of Engineers analysis projected large increases in Muskingum River corridor recreation; and maintained that these values justified 
large future investments in lock and dam improvements. Analysis by Hitzhusen et al. [13] shows that recreational use values do not offset the costs of lock and dam repair/upgrades. This is demonstrated with evidence that repairs and upgrades made in recent years have not resulted in any measurable increases in recreation use. Decreases in lock use have in fact been the norm. This evidence was combined with benefit transfer techniques and day use values for various types of recreation (e.g. boating, fishing, picnicking and visiting) common in the Muskingum Corridor.

Since use values are inadequate, non-use (existence, historic preservation) values were explored by implementing a CVM survey of willingness to pay for lock and dam repair by a sample of the adult residents of Ohio. These results suggest benefits large enough to exceed the discounted present value costs of repairing, maintaining and operating the locks and dams; the benefit cost ratio is 1.51 and the net present value $\$ 5,876,000$ (see Table 1 ).

The proposed extension of the Zane's Landing bike trail was evaluated with a similar approach. Construction cost estimates were available for the proposed trail and it was possible to get information on annual operating and maintenance costs from other trails in Ohio. The benefits were estimated by aggregating the results from the aforementioned contingent valuation survey and the forecasted trail use. Once again the findings are supportive; the benefit cost ratio is 6.49 and the net present value $\$ 11,261,000$.

The costs of zoning and improved household septic systems were determined from interviewing those involved in the provision of each. The analysis of the benefits was more complex. Both zoning and household septic systems are expected to impact residential property values, so a hedonic pricing method was chosen to estimate this effect. Hedonic pricing statistically decomposes the housing/property values into house, community, and environmental attributes and estimates the relative values of each of these attributes. In the case of household septic systems it was presumed appropriate to assess benefits accruing to other stream users besides river corridor residents. Thus, the contingent valuation survey was utilized to approximate these values and the results were combined with the hedonic estimates.

From the hedonic model it was possible to determine the effect of the presence of zoning, central sewer system, individual household septic system and river proximity on residential property values in the corridor. The aggregate values are as follows: zoning $\$ 912,000$; central sewer $\$ 678,000$; household septic systems $\$ 1,470,000$; and river proximity $\$ 637,000$. The hedonic benefits for zoning when compared with costs show a benefit cost ratio of 5.39 and NPV of $\$ 630,000$. The combined hedonic and CVM results for household septic systems (with a local government $50 \%$ cost share of installation and full coverage of repair and cleaning) showed a benefit cost ratio of 1.44 and NPV of $\$ 8,274,812$. The results of a program of full governmental subsidization were a benefit cost ratio of 1.39 and NPV of $\$ 2,051,000$. Full subsidization is not as economically viable; the benefit cost ratio is 0.72 and NPV is $-\$ 2,590,000$.

At a $10 \%$ discount rate (a discount rate commonly used in this type of analysis) it is instructive to compare and aggregate the net present value and 
benefit cost ratio results for the corridor improvements. Table 1 presents these results.

Table 1: $\quad$ Summary of aggregate benefit cost results in 1999 dollars, $\mathrm{i}=10 \%$.

\begin{tabular}{|l|c|c|c|c|}
\hline & $\begin{array}{c}\text { Present Value } \\
\text { of Benefits }\end{array}$ & $\begin{array}{c}\text { Present Value } \\
\text { of Costs }\end{array}$ & $\begin{array}{c}\text { Net Present } \\
\text { Value (B-C) }\end{array}$ & $\begin{array}{c}\text { Benefits/ Costs } \\
\text { (Ratio) }\end{array}$ \\
\hline Zoning & $\$ 774,000$ & $\$ 144,000$ & $\$ 630,000$ & 5.39 \\
\hline Septic (Cost-Sharing) & $\$ 6,692,000$ & $\$ 4,641,000$ & $\$ 2,051,000$ & 1.44 \\
\hline Bike Trail & $\$ 13,311,000$ & $\$ 2,050,000$ & $\$ 11,261,000$ & 6.49 \\
\hline Lock \& Dam & $\$ 17,511,000$ & $\$ 11,635,000$ & $\$ 5,876,000$ & 1.51 \\
\hline Total & $\$ 38,290,000$ & $\$ 18,470,000$ & $\$ 19,816,000$ & 2.07 \\
\hline
\end{tabular}

When using the benefit cost ratio efficiency criterion, the bike trail extension and zoning rank first and second respectively followed by lock and dam operation and repairs and upgraded household septic systems. With the net present value criterion, which is influenced by the scale or size of investments, the bike trail ranks first, followed by the locks and dams, the upgraded household septic systems and zoning respectively. In total, the four improvements have a net present value of $\$ 19.8$ million and a $\mathrm{B} / \mathrm{C}$ ratio of 2.07 .

\subsection{Benefit capture results}

Regarding benefit capture, the hedonic based tax revenue functions showed increases in tax revenue from zoning accruing to the cities of Zanesville and Marietta (see Table 2) to be about two times larger than the increases from improved household rural septic systems in Muskingum and Washington counties. The hedonic based tax revenue functions for school districts in Muskingum and Washington counties (see Table 3) showed six fold differences between zoning and improved septic system impacts. However, the annual revenue increases from zoning and household septic system improvements are generally larger to the school districts than to the local governments.

Table 2: Estimated annual property tax revenue increases from corridor improvements.

\begin{tabular}{|l|c|c|c|c|}
\hline City & $\begin{array}{c}\text { Tax Millage } \\
(\$)\end{array}$ & $\begin{array}{c}\text { Coefficient } \\
\text { Estimate }\end{array}$ & $\begin{array}{c}\text { Number of Houses } \\
\text { in the Area }\end{array}$ & $\begin{array}{c}\text { Tax Revenue } \\
\text { Increase (\$) }\end{array}$ \\
\hline Zoning \\
\hline Zanesville & 44.22 & 269 & 485 & 5782.21 \\
\hline Marietta & 43.18 & 269 & 464 & 5389.55 \\
\hline Septic System & 44.22 & 67 & 1002 & 2975.38 \\
\hline Muskingum & 43.18 & 67 & 726 & 2100.36 \\
\hline Washington &
\end{tabular}


Table 3: Estimated annual school district tax revenues generated by zoning and septic system.

\begin{tabular}{|l|c|c|c|c|}
\hline City & $\begin{array}{c}\text { Tax } \\
\text { Millage (\$) }\end{array}$ & $\begin{array}{c}\text { Coefficient } \\
\text { Estimate }\end{array}$ & $\begin{array}{c}\text { Number of Houses } \\
\text { in the Area }\end{array}$ & $\begin{array}{c}\text { Increase in Tax } \\
\text { Revenue (\$) }\end{array}$ \\
\hline Zoning & \multicolumn{5}{|l|}{} \\
\hline Muskingum & 24.61 & 269 & 1487 & 9844.07 \\
\hline Washington & 26.23 & 269 & 1190 & 8396.49 \\
\hline Septic & 67 & 1002 & 1652.60 \\
\hline Muskingum & 24.61 & 67 & 726 & 1275.70 \\
\hline Washington & 26.23 & 67 &
\end{tabular}

The CVM instrument was not originally designed with bid function estimation in mind, and a limited number of observations were available, but these limitations can be resolved in future work. However, the aggregate evidence on WTP from the CVM survey resulted in benefit cost ratios of 1.4 to 6.5 for the four river corridor improvements (see Table 1). This, in turn prompted two river advocacy groups, Rivers Unlimited and Community 20/20, to work with US Senator DeWine in developing a $\$ 3.4$ million appropriation request which was not ultimately funded because of the $9 / 11$ crisis. Despite the bid function limitations, there are some general conclusions that can be drawn regarding what groups of people are more likely to have positive WTP for the three amenities. (See Hitzhusen et al. [12] for more details).

\section{Conclusions and implications}

Any research endeavor has limitations and this study of the Muskingum River is no exception. In an ideal world, better water quality data and higher response rates on the CVM survey would have been preferred. More evidence on establishment and opportunity costs for zoning, and the economic value as well as any environmental consequences of using river water for American Electric Power's cooling needs in electric power generation would all improve the study results. More detailed estimation of economic internal rate of return and development of bid functions for the CVM survey results would improve the accuracy, generalization and explanation of results.

These research results have some important policy implications in spite of the limitations highlighted and the need for further research. First, the methods and results demonstrate that it is possible to develop economic metrics for the costs and benefits of selected river corridor attributes. In addition, these results provide evidence for ranking corridor improvements based on the benefit cost ratio and net present value of each attribute. However, if magnitude or scale of the attribute improvements varies considerably, the ranking of attributes according to benefit cost ratio and net present value may be different.

Benefit cost ratios greater than one and positive net present values were evident at the $10 \%$ discount rate for all Muskingum River Corridor attributes and improvements except for fully subsidized household septic systems. So, in 
general, the economic rationale for river improvement and restoration is supported. As an investment strategy one might propose to proceed by implementing corridor improvements on the basis of their relative economic efficiency based on their benefit cost ratios. Some caution must be exercised. One might expect improved septic systems, lock and dam restoration and the bike trail extension to result in increased economic well being in the Muskingum River Corridor. However, limited opportunity may exist for additional municipal zoning and hence it is unlikely that additional benefits from zoning will occur in the future.

There are some benefit capture implications from the hedonic - tax revenue and bid function results. The absolute numbers, e.g. annual property tax revenue increases from zoning in the small cities of $\$ 11,172$ and from improved household septic systems in two rural counties of \$5076 may not seem large, but at the margin these may not be trivial increases to small municipal and rural county governments. The annual increases in school district tax revenues in Muskingum and Washington counties from zoning and improved household septic systems totaled $\$ 21,169$. Explanatory evidence from the CVM bid functions can be used to target fund raising from individual citizen-consumers as indicated, but this evidence could also be strengthened and combined with the CVM aggregate WTP evidence to develop a political economy approach and generate majority support for legislative and referendum efforts. This would seem to be a promising area for future research to assist initiatives for restoration and/or protection of rivers and other natural resource systems.

One potential advantage of these economic methods and results is to reduce conflict and transaction costs in the policy process. For example, applying a common economic metric to river corridors and other natural systems may make it possible for state departments of natural resources and economic development to find more common ground in improving the well being for state citizens. Business and environmental interest groups may also be able to build more consensus and lower decision making (e.g. litigation) costs. Economic analysis of a river corridor or basin as a hydrologic unit may also facilitate cooperation across political boundaries for more optimal public policy and management of this natural resource system. This analysis is combined with analysis of seven other river systems in the Northeast U.S. in a forthcoming book from Edward Elgar Publishers in an attempt to generalize methods and results.

\section{References}

[1] Ayalasomayajula, R. Economic Valuation of River Corridor Attributes: A Hedonic and NIE Approach. Unpublished Master's Thesis, The Ohio State University, 2000.

[2] Bishop, R., Heberlein, T.A., and Kealy, M.J. "Contingent Valuation of Environmental Assets: Comparisons with a Simulated Market". Natural Resources Journal, Vol.33, pp 619-633, July 1983.

[3] Boyle, K.J. and Bergstrom, J.C. "Benefit Transfer Studies: Myths, Pragmatism and Idealism". Water Resources Research 28:657-663, 1992. 
[4] Burkhead, J. and Miner, J. Public Expenditure, Aldine, Atherton, Inc., Chicago, IL, 1971.

[5] Carson and Mitchell, Using Surveys to Value Public Goods: the Contingent Valuation Method. Washington, D.C., Resources for the Future, 1989.

[6] Dasgupta, A.K. and Pearce, D.W. Cost-Benefit Analysis: Theory and Practice, The MacMillan Press, Ltd., London, 1978.

[7] Epp, D.J. and Al-Ani, K.S. "The Effect of Water Quality on Rural Nonfarm Residential Property Values," American Journal of Agricultural Economics. 61:3:529-34, 1979.

[8] French, D. and Hitzhusen, F. "Status of Benefits Transfer in the U. S. and Canada: A Comment”, Canadian Journal of Agric Econ., July 2001.

[9] Hite, D. Welfare Measures for an Environmental Disamenity in the Residential Real Estate Market. Unpublished Ph.D. Dissertation, The Ohio State University, 1995.

[10] Hitzhusen, F.J. "Cost-Benefit Analysis: Cornerstone or Achilles' Heel of Social Science?" ESO 1230, 1984, AERS Department, The Ohio State University, Columbus, OH, USA.

[11] Hitzhusen, F.J., Editor, Benefit Cost Analysis Reader, AEDE 631, Autumn, 2005, The Ohio State University, Columbus, OH, USA.

[12] Hitzhusen, F.J., Ayalasomayajula, R. and Lowder, S. "Some Conceptual Clarification and Empirical Evidence on Benefit Caputre: A River Corridor Case," AEDE Working Paper, OSU, Sept 2002.

[13] Hitzhusen, F.J., Lowder, S. and Ayalasomayajula, R. Muskingum River Economic Valuation, AED Economics Dept., The Ohio State University, Summer, 2000.

[14] Jud, D.G. "Effects of Zoning on Single-Family Residential Property Values: Charlotte, North Carolina," Land Economics. 56:2:142-53, 1980.

[15] Pearce, D.W. and Kerry, T.R. Economics of Natural Resources and the Environment, Hemal Hemstead: Harvester Wheatsheaf, 1990.

[16] Prest, A. and R. Turney. "Cost-Benefit Analysis: A survey" Economic Journal, December 1965, pp. 683-735.

[17] Randall, A. Resource Economics: An Economic Approach to Natural Resource and Environmental Policy, Grid Publishing, Inc., Columbus, OH, 1981.

[18] Samuelson, P.A. "The Pure Theory of Public Expenditure" Review of Economics and Statistics XXXVI, pp 387-390, November 1954.

[19] United States Army Corps of Engineers. "Muskingum River Lock and Dam Study: Reconnaissance, December, 1991.

[20] Walsh, R.G., Johnson, D.M. and McKean, J.R. "Benefit Transfer of Outdoor Recreation Demand Studies. 1968-88", Water Resources Research, 28 (March 1992): 707-13. 